\title{
ガラスセラミック法で作成した $\mathrm{SrFe}_{12} \mathrm{O}_{19}$ 粒子の プラスチック磁石への応用*
}

$$
\begin{aligned}
& \text { 小田 喜 一**, 吉 尾 哲 夫** } \\
& \text { 大 岡 一 } \text { 夫 }^{* *} \text {, 全 丸 文 一*** }
\end{aligned}
$$

Kuichi Oda, Tetsuo Yoshio, Kazuo O-oka, and Fumikazu Kanamaru: Application to the Plastic-Magnet Using $\mathrm{SrFe}_{12} \mathrm{O}_{19}$ Particles Prepared by the Glass-Ceramic Method.

High coercivity $\mathrm{SrFe}_{12} \mathrm{O}_{19}$ particles were prepared by the glass-ceramic method using the glass with composition $y=1$ in the system $46.94[(1-y) \mathrm{BaO} \cdot y \mathrm{SrO}] \cdot 17.14 \mathrm{~B}_{2} \mathrm{O}_{3} \cdot 11.43 \mathrm{SiO}_{2} \cdot 24.49 \mathrm{Fe}_{2} \mathrm{O}_{3}$ (molo\%), and plastic-magnets were fabricated with the obtained particles.

$\mathrm{SrFe}_{12} \mathrm{O}_{19}$ particles $(\approx 0.3 \mu \mathrm{m}$ in diam.) were obtained by leaching the sample after a heat treatment of the glass $(y=1)$ at $875^{\circ} \mathrm{C}$ for $5 \mathrm{hr}$. The particles showed very high coercive force of $6080 \mathrm{Oe}$ and $\sigma_{\mathrm{s}}=$ $52 \mathrm{emu} / \mathrm{g}$.

$\mathrm{SrFe}_{12} \mathrm{O}_{19}$ plastic-magnet fabricated by the roll method consisted of random assembly. Values of magnetic properties were ${ }_{\mathrm{B}} \mathrm{H}_{\mathrm{C}}=1030 \mathrm{Oe}, \mathrm{B}_{\mathrm{r}}=1150 \mathrm{G}$, and $(\mathrm{B} \cdot \mathrm{H})_{\max }=0.3 \mathrm{M} \mathrm{G} \cdot \mathrm{Oe}$, however a $\mathrm{SrFe}_{12} \mathrm{O}_{19}$ plastic-magnet fabricated by the injection molding under applying magnetic field exhibited slightly preferred orientation with the values of ${ }_{B} \mathrm{H}_{\mathrm{C}}=1551 \mathrm{Oe}, \mathrm{B}_{\mathrm{r}}=1743 \mathrm{G}$, and $(\mathrm{B} \cdot \mathrm{H})_{\max }=0.7 \mathrm{M} \mathrm{G} \cdot$ Oe.

(Received October 25, 1984)

\section{I 緒 言}

著者らはガラスセラミック法を用いた $(\mathrm{Ba}, \mathrm{Sr})$-ヘキ サフェライト粒子の作成に関して，適当な条件でガラス に熱処理を施すことにより粒子径の揃った六角板状の自 形を有する(Ba，Sr)一ヘキサフェライト粒子が得られる こと，またその保磁力 $\left({ }_{\mathrm{I}} \mathrm{H}_{\mathrm{C}}\right)$ は 5500 6000 Oe の高い 值を示すととなどを明らかにしてきだ,22.乙れらハード フェライトの材料としての使用形態は, 烧結体などの 'Bulk' の形と ${ }^{3)}$ ，プラスチック磁石 ${ }^{4)}$ ，ゴム磁石 ${ }^{5)}$ ， あ るいは磁気記録材料 677 に用いられる 'Powder' の形之 に大別される.ガラスセラミック法により作成される強 磁性体粒子の忘用は，主後者の分野でその特徵が発揮 される.

本研究では，ガラスセラミック法で得られる Sr-へキ サフェライトを工業的にも重要なプラスチック磁石へ忘 用することを目的とし，得られた $\mathrm{Sr}$ 一キサフェライト の粒子径, 飽和磁化 $\left(\sigma_{\mathrm{s}}\right)$ と保磁力 $\left(\mathrm{I}_{\mathrm{I}} \mathrm{H}_{\mathrm{C}}\right)$ などの粒子特 性を調べるとともに，てれらフェライト粒子を用いてプ ラスチック磁石を試作しその磁気特性について検討した 結果について報告する.

\section{II 実 験 方 法}

\section{【I-1 試料の作成}

フラックスとしてのガラス組成は著者らがすでにその 結晶析出挙動を明らかにしている $46.94\{(1-y) \mathrm{BaO} \cdot y$ $\mathrm{SrO} \cdot 17.14 \mathrm{~B}_{2} \mathrm{O}_{3} \cdot 11.43 \mathrm{SiO}_{2} \cdot 24.49 \mathrm{Fe}_{2} \mathrm{O}_{3}$ (mo \%) 系 で組成 $y=1$ を採用した. 充分に乾燥した試薬特級 $\mathrm{Sr}$ $\mathrm{CO}_{3}, \mathrm{~B}_{2} \mathrm{O}_{3}, \mathrm{SiO}_{2}, \alpha-\mathrm{Fe}_{2} \mathrm{O}_{3}$ 老所定量科量して乳錸で混合 し, 容器に白金ルッボを用いシリコニット電気哣中で $1350^{\circ} \mathrm{C} 2 \mathrm{hr}$ 溶融後, 急冷王延してガラス試料を得た。 得られたガラス試料蛙 $300^{\circ} \mathrm{C} / \mathrm{hr}$ の昇・降温速度で $875^{\circ} \mathrm{C}$ $5 \mathrm{hr}$ 熱処理を行った. 熱処理試料を粉砕後, 希塩酸溶 液（5\%）でガラスマトリックスを溶解除去して析出粒 子を取り出した。得られた粒子はX線回折にて $\mathrm{Sr}$ 一キ サフェライトのみであるととを確認した。

口-2 測定方法

フェライト粒子の観察には日本電子 TEM-100CX- П 老用い，磁気特性の測定には理研電子 BHV-3.5 振動試

* 昭和59年10月25日受理.

** 岡山大学工学部非粘晶材料研究施設, 7700 岡山市津島 *** 大阪大学産業科学研究所, T565 吹田市山田上. 


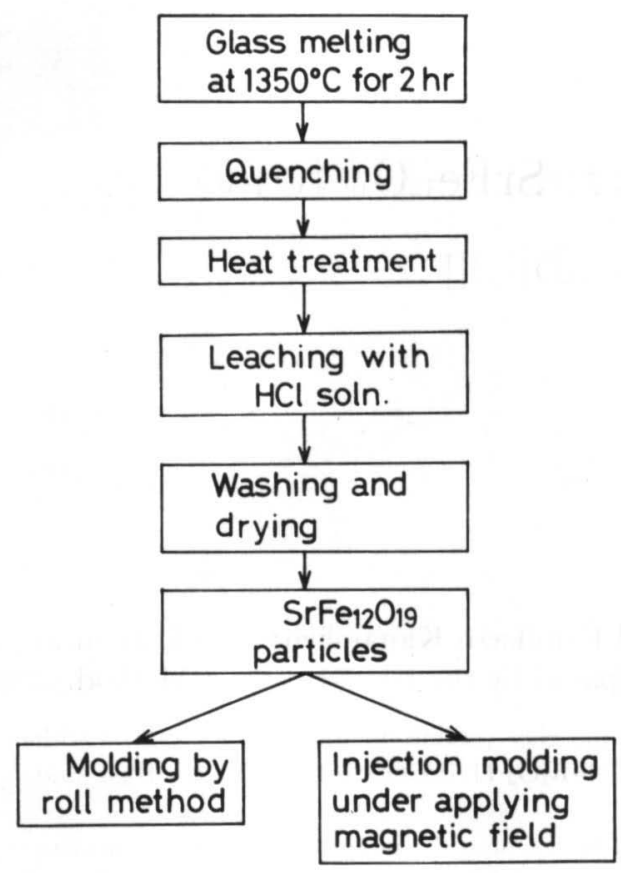

Fig. 1 Fabrication process of $\mathrm{SrFe}_{12} \mathrm{O}_{19}$ plastic-magnet.

料型磁化特性自動記録装置之横河電機製作所3257直流磁 化特性自動記録装置を用いて室温で行った.

磁気測定用試料は，バインダーとして塩化ビニール系 樹脂を用いたロール法とナイロン系樹脂を用いた磁場中 での射出成形法によるプラスチック磁石として成形した. 両者の成形法のフロチャートを Fig. 1 亿示す.

\section{III 結果と考察}

\section{III-1 フェライト粒子の特性}

Photo. 1 飞得られた $\mathrm{Sr}$ 一キキサフェライト粒子の TEM 観察結果を示す. 写真からわかるように $\mathrm{Sr}$-ヘキ サフェライトでは $\approx 0.3 \mu \mathrm{m}$ (in diam) 程度の六角板状 の自形を有する粒子か認められガラスセラミック法の特 徵として, 粒子径の揃ったあのが得られることがわかる. 本実験で用いたガラス組成では $\approx 0.3 \mu \mathrm{m}$ (in diam) 以 上の大きな粒子は得るととは出来なかったが，てれは前 報であ明らかにしたように $\mathrm{Sr}$-ヘキサフェライトの析出 過程によるものと言える ${ }^{122}$.

Table 1 亿得られた $\mathrm{Sr}$-ヘキサフェライト粒子の特性 を示す. 室温での飽和磁化 $\left(\sigma_{\mathrm{s}}\right)$ は粒子径が比較的小さ

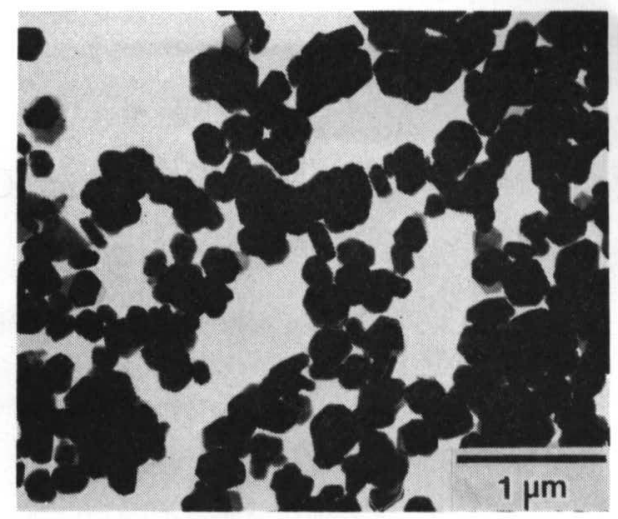

Photo. 1 Electronmicrograph of $\mathrm{SrFe}_{12} \mathrm{O}_{19}$ particles prepared by the glass-ceramic method ( $\mathrm{SrFe}_{12} \mathrm{O}_{19}$ particles obtained by leaching the glass heat-treated at $875^{\circ} \mathrm{C}$ for $5 \mathrm{hr}$ )

いために $\sigma_{\mathrm{s}}=52 \mathrm{emu} / \mathrm{g}$ とその単結晶の值 $(74.3 \mathrm{emu} /$ $\mathrm{g})^{8)}$ よりあかなり低い值を示した。 しかし, 保磁力 $\left({ }_{\mathrm{I}} \mathrm{H}_{\mathrm{C}}\right)$ は $6080 \mathrm{Oe}$ と Stoner-Wohlfarth 理論" に基づく 計算値 $8200 \mathrm{Oe}$ の $74 \%$ 程度に達した. 従って, ヘキサフ エライトではその粒子径が $0.5 \mu \mathrm{m}$ 以下になると superparamagnetic な挙動を示しその粒径とともに $\sigma_{\mathrm{s}}$ は減 少しはじめると考えられる. 一方, Ba-ヘキサフェライ トでも, 単磁区臨界粒子径（計算値）近くでの保磁力 $\left({ }_{\mathrm{I}} \mathrm{H}_{\mathrm{C}}\right)$ はその計算值 $(7100 \mathrm{Oe})$ よりかなり低い值を示 し, Shirk らの結果では, 粒子径 $0.5 \mu \mathrm{m}$ (in diam.) の 時保磁力 $\left({ }_{\mathrm{I}} \mathrm{H}_{\mathrm{C}}\right)$ は極大值 $5350 \mathrm{Oe}$ を示しているととが 報告されている(10). 以上のような粒子径と保磁力 $\left({ }_{1} \mathrm{H}_{\mathrm{C}}\right)$ の実験值と理論計算値との差違の原因としては, 実験的 に得られるへキサフェライト粒子か球形でなく六角板状 をしているために, あはや $1 \mu \mathrm{m}$ 程度の大きさでは磁化 反転モードが異なり部分的に単磁区から多磁区への遷移 領域での磁壁移動による保磁力の低下, あるいは単なる 回転モードだけではなく ‘fanning mechanism', 'curling', 'buckling'モードで磁化の反転が起とり保磁力 $\left({ }_{\mathrm{I}} \mathrm{H}_{\mathrm{C}}\right)$ が 低下しているあの之推測される ${ }^{11,12,13)}$.

\section{III-2 プラスチック磁石への応用}

Fig. 2 に本実験で得られた $\mathrm{Sr}$-ヘキサフェライト粒子 を用いて作成したプラスチック磁石の I-H curve を, Table 2 にその磁気特性值を示す. Fig. 2-a) はロール法 で作成したものであるが，I-H curve は単磁区粒子の random assembly とよく似た形を示しほとんど配向性は

Table 1 Characteristics of $\mathrm{SrFe}_{12} \mathrm{O}_{19}$ particles prepared by the glass-ceramic method. (at room temp.)

\begin{tabular}{|c|c|c|c|c|c|c|}
\hline Sample & $\begin{array}{c}\text { Saturation } \\
\text { magnetization } \\
(\text { emu/g) }\end{array}$ & $\begin{array}{l}\text { Coercive } \\
\text { force }\left({ }_{I} \mathrm{H}_{\mathrm{C}}\right) \\
(\mathrm{Oe})\end{array}$ & $\begin{array}{c}\text { Specific } \\
\text { surface area } \\
\left(\mathrm{m}^{2} / \mathrm{g}\right)\end{array}$ & $\begin{array}{c}\text { Particle size } \\
\text { (in diam.) } \\
(\mu \mathrm{m})\end{array}$ & $\begin{array}{l}\text { Switching field } \\
\text { of distribution } \\
(\mathrm{G} / \mathrm{Oe})\end{array}$ & $\begin{array}{c}\text { Ratio of particle } \\
\text { dianeter to thickness } \\
(-)\end{array}$ \\
\hline $\mathrm{SrFe}_{12} \mathrm{O}_{19}$ & 52 & 6080 & 29.9 & $\approx 0.3$ & 0.316 & $\approx 4$ \\
\hline
\end{tabular}


Table 2 Magnetic properties of $\mathrm{SrFe}_{12} \mathrm{O}_{10}$ plastic-magnets.

\begin{tabular}{|c|c|c|c|c|c|c|c|}
\hline Plastic-magnet & $\begin{array}{l}\text { Density } \\
\left(\mathrm{g} / \mathrm{cm}^{3}\right)\end{array}$ & $\begin{array}{c}\text { Saturation } \\
\text { magnetic } \\
\text { fux density }\left(\mathrm{B}_{\mathrm{s}}\right) \\
(\mathrm{G})\end{array}$ & $\begin{array}{c}\text { Residual } \\
\text { magnetic } \\
\text { flux density }\left(\mathrm{B}_{\mathrm{r}}\right) \\
(\mathrm{G})\end{array}$ & $\begin{array}{c}\text { Coercive } \\
\text { force } \\
(\mathrm{BHC}) \\
(\mathrm{Oe})\end{array}$ & $\begin{array}{c}\text { Coercive } \\
\text { force } \\
\left(\mathrm{I} \mathrm{H}_{\mathrm{c}}\right) \\
(\mathrm{Oe})\end{array}$ & $\begin{array}{l}\text { Maximum energy } \\
\text { product }(\mathrm{B} \cdot \mathrm{H})_{\max } \\
\quad(\mathrm{M} \mathrm{G} \cdot \mathrm{Oe})\end{array}$ & $\begin{array}{l}\text { Orientation } \\
\text { (\%) }\end{array}$ \\
\hline $\begin{array}{l}\mathrm{SrFe}_{12} \mathrm{O}_{19} \\
\text { (roll method) }\end{array}$ & 2.95 & 1660 & 1150 & 1030 & 6030 & 0.3 & 55.3 \\
\hline $\begin{array}{l}\mathrm{SrFe}_{12} \mathrm{O}_{19} \\
\text { (injection molding) }\end{array}$ & 3.11 & 2106 & 1743 & 1551 & 6360 & 0.7 & 69 \\
\hline $\begin{array}{l}\mathrm{BaFe}_{12} \mathrm{O}_{19} \\
\text { (commercial product) }\end{array}$ & 3.4 & 3050 & 2350 & 1940 & 2730 & 1.2 & 80 \\
\hline
\end{tabular}
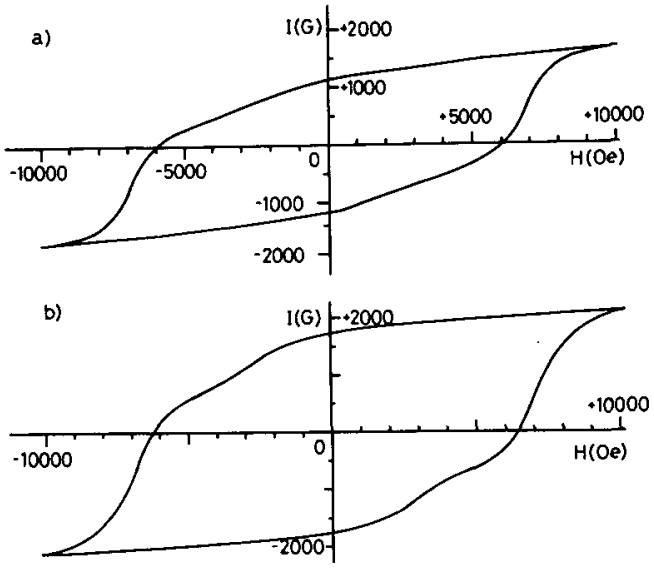

Fig. 2 I-H curves for $\mathrm{SrFe}_{12} \mathrm{O}_{10}$ plastic-magnets.

a) $\mathrm{SrFe}_{12} \mathrm{O}_{1}$ plastic-magnet fabricated by the roll method.

b) $\mathrm{SrFe}_{12} \mathrm{O}_{19}$ plastic-magnet fabricated by the injection molding under applying magnetic field.

認められず, ${ }_{\mathrm{B}} \mathrm{H}_{\mathrm{C}}=1150 \mathrm{G},{ }_{\mathrm{B}} \mathrm{H}_{\mathrm{C}}=1030 \mathrm{Oe},(\mathrm{B} \cdot \mathrm{H})_{\max }=$ $0.3 \mathrm{MG} \cdot \mathrm{Oe}$ とかなり低い值を示した. Fig. 2-b) は磁場 中での射出成形により作成したものであるが, I-Hcurve からロール法で作成したものよりす幾分配向性は良好で $\mathrm{B}_{\mathrm{r}}=1743 \mathrm{G}, \quad{ }_{\mathrm{B}} \mathrm{H}_{\mathrm{C}}=1551 \mathrm{Oe}, \quad(\mathrm{B} \cdot \mathrm{H})_{\max }=0.7 \mathrm{MG} \cdot \mathrm{Oe}$ のものが得られた. Table 1 より六角板状フェライト粒 子の厚さに対する粒于径比が 4 程度のものでは磁場配向 法が有利であると考えられる，本実験で得られたプラス チック磁石の磁気特性は市販品と比較すると ${ }_{\mathrm{B}} \mathrm{H}_{\mathrm{C}}, \mathrm{B}_{\mathrm{r}}$, $(\mathrm{B} \cdot \mathrm{H})_{\max }$ は劣るが ${ }_{1} \mathrm{H}_{\mathrm{C}}$ は $6000 \mathrm{Oe}$ 程度とかなり高い あのである.このことは Photo. 1 で見られる粒子径の 均一性からあうかがえるように ${ }_{1} \mathrm{H}_{\mathrm{C}}$ の分布の広がりを 示す指数 S. F. D (Switching Field of Distribution) の 値が 0.3 程度とかなり小さいととから考えてガラスセラ ミック法を用いるととにより達成された特性と言えるで あるう。

\section{IV ま}

ガラスセラミック法を用いた高保磁力 $\mathrm{SrFe}_{12} \mathrm{O}_{19}$ 粒子 の作成，ならびに得られた粒子を用いてプラスチック磁
不を試作し，その磁気特性を調べた。その結果を要約す る之次の通りである.

1) $46.94\{(1-y) \mathrm{BaO} \cdot y \mathrm{SrO}\} \cdot 17.14 \mathrm{~B}_{2} \mathrm{O}_{3} \cdot 11.43 \mathrm{SiO}_{2}$. $24.49 \mathrm{Fe}_{2} \mathrm{O}_{3}(\mathrm{~mol} \%)$ 組成のガラス系で, $y=1$ 組成の ガラスを $875^{\circ} \mathrm{C} 5 \mathrm{hr}$ 熱処理後，ガラスマトリックスを leaching することにより $\approx 0.3 \mu \mathrm{m}$ の粒子径の揃った $\mathrm{SrFe}_{12} \mathrm{O}_{19}\left(\mathrm{I}_{\mathrm{I}} \mathrm{H}_{\mathrm{C}}=6080 \mathrm{Oe}, \sigma_{\mathrm{s}}=52 \mathrm{emu} / \mathrm{g}\right.$ at room temp.) を得た。

2）本実験で得られた $\mathrm{SrFe}_{12} \mathrm{O}_{19}$ 粒子を用いてプラスチ ック磁石を試作した。ロール法で作成した $\mathrm{SrFe}_{12} \mathrm{O}_{19}$ プ ラスチック磁不はほとんど配向性は認めら㧈ず， ${ }_{\mathrm{B}} \mathrm{H}_{\mathrm{C}}=$ $1030 \mathrm{Oe}, \mathrm{B}_{\mathrm{r}}=1150 \mathrm{G},(\mathrm{B} \cdot \mathrm{H})_{\max }=0.3 \mathrm{MG} \cdot \mathrm{Oe}$ であっ た。一方，磁場中で射出成形して得られた $\mathrm{SrFe}_{12} \mathrm{O}_{19}$ のプラスチック磁石は幾分配向性の问上が認められ $\mathrm{B}_{\mathrm{r}}$ $=1743 \mathrm{G},{ }_{\mathrm{B}} \mathrm{H}_{\mathrm{C}}=1551 \mathrm{Oe},(\mathrm{B} \cdot \mathrm{H})_{\max }=0.7 \mathrm{MG} \cdot \mathrm{Oe}$ の磁 気特性を示した。

\section{文献}

1) 金丸, 小田, 吉尾, 島田, 高橋: 粉体および粉末冶金, 28 (1981), 70.

2）小田, 吉尾, 高橋: 粉体抢よび粉末治金, 29 (1982), 39.

3) J. Smit and H. P. J. Wijn: Ferrites, Philips Technical Library, Eindhoven, The Netherlands (1959), 321.

4) 浜野: 工業材料, 27 (1979), 85.

5) 邻田, 他編：硬質磁性材料（磁気工学講座 3) 丸善 (1976), 144.

6) T. J. Szczech and R. E. Fayling: IEEE Trans. Mag., MAG-12 (1976), 707.

7) 保坂：電子通信学会誌, MR80-42 (1980), 9.

8) B. T. Shirk and W. R. Buessem: J. Appl. Phys., 40 (1969), 1294.

9) E. C. Stoner and E. P. Wohlfarth: Phil. Trans. Royal Soc., 240A (1948), 599.

10) B. T. Shirk and W. R. Buessem: IEEE Trans, Mag., MAG-7, (1971), 659.

11) A. E. Berkowitz and E. Kneller: Magnetism and Metallurgy 1 Academic Press (1969), 356.

12) I. S. Jacobs and C. P. Bean: Phys. Rev., 100 (1955), 1060.

13) E. H. Frei et al.: Phys. Rev., 106 (1957), 446. 